\title{
Empreendedorismo Familiar: Como esse Modelo de Gestão pode Afetar a Empresa
}

\author{
Suzana Siebra Alves Campos ${ }^{1}$; Piedley Macedo Saraiva ${ }^{2}$
}

\begin{abstract}
Resumo: Os empreendimentos familiares possuem grande relevância no cenário mundial, tanto no setor econômico que afeta diretamente a elevação do PIB, como socialmente para geração de empregos diretos. Este assunto vem sendo abordado com grande ênfase no mercado brasileiro, pois $90 \%$ das empresas ativas no Brasil são familiares e contribuem para o crescimento do país. O objetivo do presente artigo foi identificar a influência familiar na gestão do negócio e como elas podem afetar seu desempenho no mercado. A metodologia envolveu pesquisa bibliográfica exploratória de abordagem qualitativa. Os resultados levaram a crer que as empresas familiares são empreendimentos viáveis, porém que necessitam de uma gestão voltada para a descentralização do poder e, de um planejamento estratégico que considere a sucessão da empresa no mercado.
\end{abstract}

Palavras-chave: Empresas familiares, gestão familiar, organizações.

\section{Family Entrepreneurship: How this Management Model Can Affect the Company}

\begin{abstract}
Family enterprises have great relevance in the world scenario, both in the economic sector that directly affects the rise of the GDP and also socially to generate direct jobs. This subject has been approached with great emphasis in the Brazilian market, since $90 \%$ of the active companies in Brazil are familiar and contribute to the growth of the country. The objective of this article was to identify the family influence in the management of the business and how they can affect its performance in the market. The methodology involved exploratory bibliographic research with a qualitative approach. The results led us to believe that family-owned enterprises are viable enterprises, but they need a management focused on the decentralization of power, and strategic planning that considers the succession of the company in the market.
\end{abstract}

Keywords: Family business, family management, organizations.

\section{Introdução}

Os empreendimentos familiares possuem grande relevância no cenário mundial, tanto no setor econômico que afeta diretamente a elevação do PIB, como socialmente para geração de empregos diretos (LANSBERG, 1997).

\footnotetext{
${ }^{1}$ Graduação em Administração pela Faculdade Paraíso do Ceará, Brasil. suzanasiebra@ hotmail.com;

${ }^{2}$ Mestre em administração de empresa pela Unisal (Universidade de San Lourenço), mestrando em desenvolvimento regional pela UFCA, professor titular da disciplina de empreendedorismo da Faculdade Paraíso. piedley@aller.co.
} 
Este assunto vem sendo abordado com grande ênfase no mercado brasileiro, pois $90 \%$ das empresas ativas no Brasil são familiares e contribuem para o crescimento do país. Pode-se perceber a importâncias deste tipo de empresa no Brasil pelo surgimento nos primórdios da colonização portuguesa, tendo em vista que as capitanias hereditárias faram os disseminadores desse tipo de empreendimento (MARTINS et al, 1999).

Segundo a revista Fortune 500, citado por Gersick (2006), no Brasil as empresas familiares correspondem a cerca de mais de $80 \%$ de empresas privadas, gerando cerca de $3 / 5$ de receitas e 2/3 de empregos (OLIVEIRA, 1999).

Entre outas definições pode-se definir empresa familiar como empresa que possui origem e desenvolvimento familiar, como também empresas que mantem no seu corpo diretivo membros da família por várias gerações. Toda e qualquer empresa está sujeita a ameaças que ocorrem diariamente no mercado, sejam elas politicas, econômicas, saciais ou tecnológicas que influencias diretamente na execução de suas atividades. Já as empresas familiares estão sujeitas a ameaças entre si, que atinge não só o desempenho da empresa, bem como a convivência familiar, envolvendo questões financeiras, de gestão e sucessão.

Mediante essas particularidades as empresas familiares apresentam certas vantagens como a lealdade e total compromisso com o negócio, quem podem resultar no crescimento significativo. Mas também há desvantagens que caso não sejam geridas de forma correta podem levar a empresa a falência.

Devido tal influência significativa deste tipo de empresa no mercado o objetivo geral do presente artigo baseia-se em identificar a influência familiar na gestão do negócio e como elas podem afetar seu desempenho no mercado Os objetivos específicos será entender o conceito de gestão familiar, identificar organizações que possuem gestão familiar e avaliar a influência do modelo de gestão no negócio.

A problemática teve origem com a seguinte indagação: qual a influência da gestão familiar nos novos negócios? Partindo deste pressuposto, pois os negócios ao se iniciarem, em sua maioria, são gerenciados por familiares, através desta pesquisa buscou-se identificar se este modelo de gestão é viável. 


\section{Referencial Teórico}

Empresa é definida como um conjunto organizações e subdividido para oferecer produto e/ou serviços ao s consumidores, sejam eles por necessidade ou desejo. Dentre as quais se destacam as empresas familiares que possuem uma quantidade significativa em participação de mercado. Segundo dados do Instituto Brasileiro de Geografia e Estatística (IBGE) e do Serviço Brasileiro de Apoio a Micro e Pequenas Empresa (SEBRAE), afirmam que mais de 90\% das empresas que atuam no país são familiares. Mesmo sendo consideras a principal fonte de renda, o que resulta para o país em um PIB de 65\%, pesquisas apontam que a cada 100 empresas ativas, apenas 30 conseguem permanecer no mercado na primeira linha de sucessão e cinco chegam a terceira.

Para Ricca Neto (1998, p. 9), as empresas familiares possuem um diferencial que a distingue das demais organizações, que são: os laços de família que garantem o direito de ocuparem o cargo na empresa. Deste modo as empresas familiares tem o intuindo de unir a convivência a realização de tarefas no ambiente laboral, ondem que acreditam que permita um trabalho mais harmonioso. Neste sentido percebe-se um melhor desenvolvimento da empresa, visto que o interesse e esforços tanto físicos, pessoais e financeiros estão unificados para o crescimento empresarial, consequentemente a empresa só gestão familiar possuem grandes vantagens que possibilitam viabiliza-las. Entretanto, ocorrem alguns problemas com esse tipo de administração que pode ser considerada liberal por não serem identificadas e determinadas habilidades e competências de cada colaborador com seu respectivo cargo, ou também a centralização do poder e a não delegação de tarefas.

Conforme Ricca (2001):

\footnotetext{
"A maior preocupação das empresas familiares é a sua sobrevivência. A maioria delas enfrenta problemas existenciais ou estratégicos, isto é, dificuldades relacionadas à inadequação, tanto na utilização, quanto na escolha dos recursos disponíveis para o alcance das vantagens de mercado."
}

Deste modo, muitas são as razões que levam uma empresa ao declínio, o que abatem abem sobre os membros da família e a levam para declínio. Os problemas de os de mais variados tipos e de diversos níveis de complexidade que iram variar com o porte de cada empresa. 


\section{Empreendedorismo}

O termo empreendedor surgiu na França e significa "assumir riscos e começar algo novo". Já o termo empreendedorismo é a iniciativa de começar algo novo nos negócios ou até mudanças de melhorias em empresas.

Shumpeter (1984) defendeu que o empreendedor é alguém com desejo de inovar no mercado, ou seja, que possua potencial de converter uma ideia em um negócio bem sucedido. Assim, o empreendedor tem a capacidade de modificar a economia com a inserção de novos produtos e/ou serviços do mercado.

Para Frank (1967) e Peter Drucker (1970), o empreendedorismo está relacionado a correr riscos impostos através da inovação, assegurando que "o empreendedor é a pessoa que destrói a ordem econômica existente graças à introdução no mercado de novos produtos/serviços, pela criação de novas formas de gestão ou pela exploração de novos recursos, materiais e tecnologia". Deste modo, os empreendedores "não são simplesmente provedores de mercadorias ou de serviços, mas fontes de energia que assumem riscos em uma economia em constante transformação e crescimento." (CHIAVENATO, 2007, p.18).

Para inovar o empreendedor necessita de recursos, estes que podem ainda nem existir, por isso deve estar sempre em busca constante pelo conhecimento sempre tendo em vista a necessidade do indivíduo. Os empreendedores têm características distintas, por isto podem ser classificados em diversos tipos como o empreendedor nato que já nasce que a habilidade de empreender, e o empreendedor que aprende cuja característica está na visualização de uma oportunidade de mercado e decide gerir seu próprio negócio e também o empreendedor por necessidade que iniciam um empreendimento autônomo por não possuir alternativa para obtenção de renda.

\section{Empreendedorismo no Brasil}

O empreendedorismo no Brasil teve início na década de 1920, por meio do desenvolvimento de mais de 4.000 indústrias que era subsidiadas e protegidas que possuía autorização do governo mais concorrência nacional. A partir da década de 1990, o empreendedorismo ganhou destaque no Brasil com a abertura da economia. Com a implantação do SEBRA (antes CEBRAE), o empreendedorismo foi ganhando espaço do mercado, e 
alavancado o desenvolvimento empresarial. Com isso varias empresas de renomes no mercado atual foram sendo fundadas, com O Pão de Açúcar, umas das maiores empresas varejistas do país, como também o Grupo Sadia, hoje Brasil Fudes, resultado de uma fusão entre Sadia e Perdigão.

De acordo com uma pesquisa realizada pela Global Entrepreneurship Monitor (GEM) e divulgada pelo SEBRAE (2010), o empreendedorismo no Brasil apresentou uma taxa de crescimento significativa em relação aos países que compõe o G20, grupo dos maiores países que fazem parte do BRICS.

No ano de 2010, o Brasil conseguiu atingir a taxa de empreendedorismos de 17,5\% para empresas com ate 3,5 anos de mercado, um crescimento considerável em relação ao ano anterior, 2009, onde obteve apenas 15,3\%. Deste modo obtêm-se o dado de que a cada 100 indivíduos brasileiros 17 possuem o perfil de empreendedores.

Entretanto, é importância ressaltar que no Brasil apenas 14\% dos empreendedores possuem formação superior e $30 \%$ não concluíram o ensino fundamental. De acordo com dado do Global Entrepreneurship Monitor no ano de 2011, o Brasil possuía 27 milhões de assuntos com faixa etária entre 18-64 anos que estão iniciando seu próprio negócio, o que resulta em 1 empreendedor a cada 4 brasileiros, essas dados elevam o Brasil a posição de terceiro lugar entre países com perfil empreendedor.

Deste modo, iniciativas tanto por parte do empreendedor como por parte do governo são de extrema importância para o crescimento do país, seja com intuito de desenvolver no ensino ou incentivando a abertura de novas empresas, já que o governo de proem a oferecer subsídios que fomente a abertura de empreendimentos no país.

\section{Gestão Familiar}

Atualmente as empresas familiares fazem parte de mais de $90 \%$ das empresas existente no Brasil, onde temos empresas de grande porte que conseguiram destacar-se no mercado. Entretanto, muitas dessas empresas com perfil familiar não conseguem permanecer no mercado até sua terceira geração, onde a primeira geração tem como característica a idealização do patrimônio físico a segunda desfruta desse patrimônio e terceira erradica a empresa, na maioria das vezes. 
Lethbridge (1997, p. 7), comenta que as empresas familiares podem ser caracterizadas em três modalidades:

a) Empresa familiar tradicional: o capital é fechado, não possui transparência administrativa nem financeira e possui poder centralizador nos negócios da família;

b) Empresa familiar híbrida: o capital é aberto, mas a familiar ainda detém controle sobre o negócio, porém, há maior transparência de informações;

c) Empresa com influência familiar: as ações em sua maioria estão no poder do mercado, no entanto, mesmo a família afastada da empresa mantem influencia estratégica por possuir maior controle das ações.

A gestão familiar possui muitas vantagens e desvantagens que podem levar ou não o negócio ao declínio, tudo depende do posicionamento que a família adota para o gerenciamento do empreendimento.

\begin{abstract}
As empresas familiares possuem o que podemos denominar de atributos bivalentes, isto é, características que podem ser, ao mesmo tempo, vantagens ou desvantagens dependendo da forma como as empresas são conduzidas, como, por exemplo, a simultaneidade de papéis desempenhados pelos membros da empresa familiar, o envolvimento emocional e afetivo das pessoas que nela trabalham a identidade compartilhada dos parentes, sua história de vida comum e sua linguagem particular. (ADACHI, 2006, p. 49)
\end{abstract}

Com base no que foi citado, podemos concluir que por que a empresa seja estruturada com laços familiares, se não houver uma gestão estratégica foca em resultados com um planejamento estabelecido, não será possível desenvolver um fluxo de trabalho para que seja possível uma boa sucessão familiar, que podem ser realizados por meio de treinamento com especialistas.

\title{
Comportamento da Gestão
}

As empresas familiares possuem histórico de serem construídas com a personalidade do fundador juntamente com a trajetória da família, que tem como intuito que suas gerações futuras possuem controle sobre o negócio. Pois ele, fundador, é quem determina as culturas e cresças que serão adotadas na empresa e devem ser seguidas por todos os funcionários. Muitas dessas empresas familiares são formadas por sócios de famílias diferentes, mas que possuem o mesmo objetivo em comum. 
Os laços de família constituem um fator, entre outros, que determina a sucessão nos cargos administrativos; esposas ou filhos dos atuais ou antigos dirigentes máximos encontram-se no conselho administrativo; as ações praticadas por um membro da família refletem-se na reputação da empresa, independentemente de sua ligação na administração; a posição do parente na firma influi em sua situação na família; cada membro da família precisa chegar a um acordo quanto às suas relações com a empresa ao determinar sua própria carreira a seguir (DONNELLEY, 1976).

Mosimann e Fisch (1999) abordam que as crenças e os valores dos proprietários, afetam diretamente nos valores e crenças da organização que se tornarão as diretrizes e a política organizacional que irá nortear o negócio. Deste modo é importante entender o comportamento da gestão desde sua concepção para que possa ser moldado na organização.

Atualmente, são comuns empresas familiares não possuírem uma gestão totalmente com membro familiares, pois muitos de seus descendestes não querem desemprenhar cargo de gestão nas empresas, isso resulta no inicio de conflitos que afetam o desenvolvimento da empresa. Com fundadores imprudentes, o patrimônio da empresa passa a ser utilizado de forma indevida resultando em uma má formação da empresa e distorções de valores tanto para funcionários como para membros da família que fazem parte da empresa, provocando sérios problemas no desenvolvimento sucessórios.

De acordo com os três círculos de Gersick et al. (1997), observado na figura 1 abaixo, é possível a identificação de sete setores diferente em uma organização que estão distribuídos da seguinte forma: setor 1: membro da família, que não é proprietário e nem funcionário; setor 2: que não é acionista ou sócios, que não são membros e nem trabalham na empresas; setor 3: funcionários , que não é membro da família e não fazem parte da empresa; setor 4: proprietário que é faz parte da família mas não trabalha na empresa; setor 5: proprietário que trabalha na empresa , mas não faz parte da família; setor 6: membro da família que é funcionário, mas não é proprietário; setor 7: é membro da família e é proprietário da empresa.

Este modelo, tem como intuído, segundo Gersick et al. (1997), o entendimento da empresas familiares em três perspectivas- propriedade, família e gestão. Deste modo qualquer membro de uma empresa familiar pode fazer parte de um dos setores a partir da sobreposição dos círculos, oque resulta em uma visão ampliada e completa da complexidade de uma empresa familiar. 
Figura 1- O Modelo de três circulos

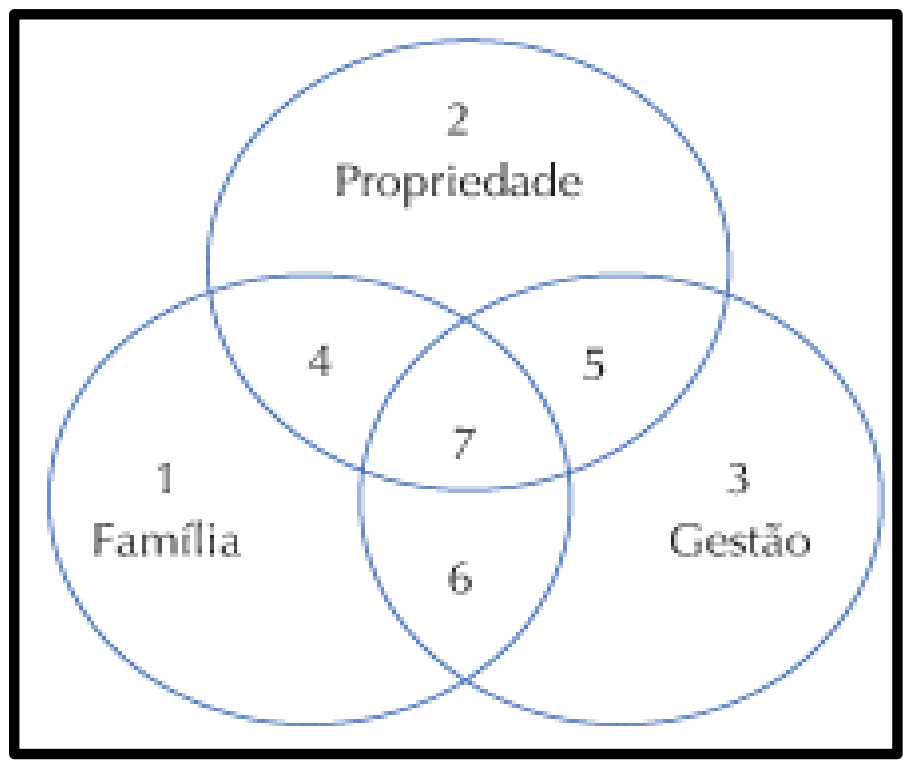

Fonte: Gersick et al. (1997, p.6)

\section{Metodologia}

O estudo em questão será realizado através de pesquisa exploratória bibliográfica de abordagem qualitativa. Exploratória, pois busca o maior número de informações possíveis, facilitando a compreensão do tema (ANDRADE, 2003), com intuito de mensurar dados obtidos em entrevistas com empresas que se enquadram no tema abordado. Silva (2003) menciona que a pesquisa de cunho exploratório é utilizada em área que possuem pouco conhecimento, proporcionando, desta forma, mais domínio sobre o tema, tornando-o mais compreensível, ou ainda o estabelecimento de novas hipóteses em relação ao assunto em questão. Deste modo a pesquisa exploratória tem como objetivo o aprofundamento dos conceitos básicos sobre um tema específico, que auxilia no entendimento de questionamentos existentes no tema.

A pesquisa bibliográfica é essencial no desenvolvimento de qualquer trabalho acadêmico, por permitem relacionar conceitos e teorias abordados por diferentes autores que pesquisaram e analisaram sobre temas mencionados em diversas pesquisas. São vários os autores que conceituam o que é a pesquisa bibliográfica, entre então alguns defendem como uma pesquisa objetiva.

A pesquisa bibliográfica procura explicar um problema a partir de referências teóricas publicadas em documentos. Pode ser realizada independentemente ou como parte da pesquisa descritiva ou experimental. Em ambos os casos, busca conhecer e analisar as 
contribuições culturais ou cientificas do passado existente sobre determinado assunto, tema ou problema. (CERVO, BERVIAN, 1996 p. 48).

Conforme o tema proposto na pesquisa, a pesquisa bibliográfica, é a metodologia adequada, pois serão utilizados vários conceitos como forma de evidenciar as principais características das empresas familiares. Para Gil (1999, p. 65), a pesquisa bibliográfica possui algumas vantagens "a principal vantagem da pesquisa bibliográfica reside no fator de permitir ao investigador a cobertura de uma gama de fenômenos muito mais ampla do que aquela que ele poderia pesquisar diretamente".

Segundo Mattar (2001), esse estudo permite ao pesquisador a absorção de maior conhecimento em relação ao tema abordado no referido artigo. Para Martins (2002), é de extrema importância a procedência do levantamento bibliográfico, visto que, possua suporte para fundamentação teoria, pois este suporte será indispensável para o desenvolvimento do estudo e posteriormente dará suporte para as considerações finais, pois são necessários fundamente que comprovem o estudo que passaram mais credibilidade ao assunto.

\section{Análise de resultados}

A pesquisa foi realizada em 3 empresas situadas na região CRAJUBAR, sendo empresas que estão dentro do perfil abordado no presente artigo. Foi aplicado um questionário com oito perguntas quantitativas, que tinham como intuito, de entender o perfil das empresas e as principais dificuldades no gerenciamento do negócio. Deste modo foi possível obter as seguintes respostas:

Figura 2 - Localização

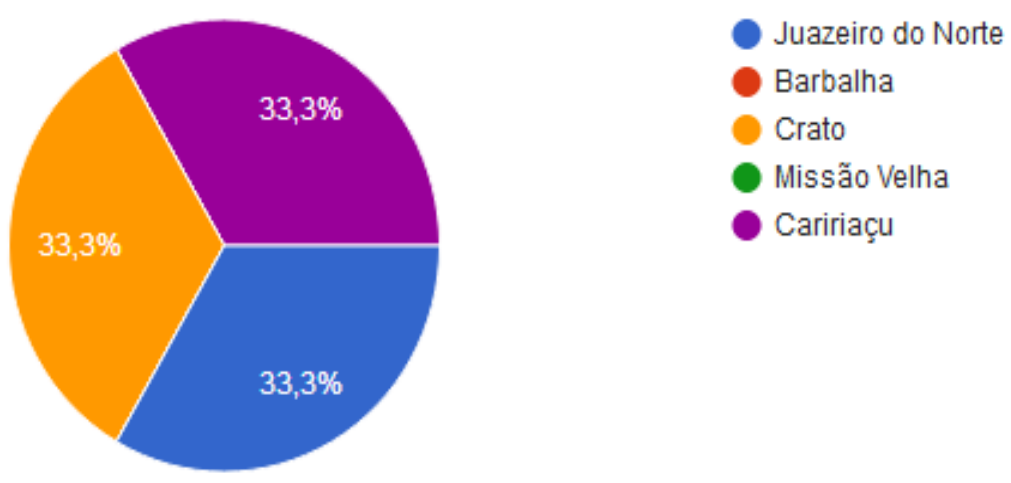

Fonte: Dados da pesquisa 
A Figura 2 mostra a locaização de cada empresa intrevistada na região CRAJUBARCrato, Juazeiro do Norte e Barbalha, esse cidades detem o maior registro de empresas com classificação familair como tambem o melhor desenvolvimento da região do Cariri cearence.

Figura 3 - Classificação da Empresa

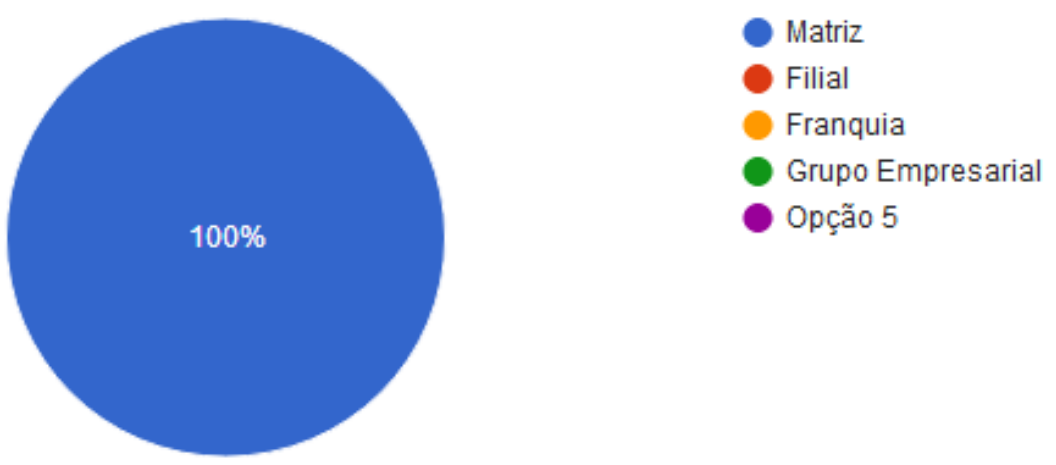

Fonte: Dados da pesquisa

A Figura 3 mostra a classificação das empresas, onde $100 \%$ responderam que são empresas matriz, isso retrata uma das características predominantes nos empreendimentos familiares que é a centralização dos negócios e o não investimento em filiais.

Figura 4 - Segmento

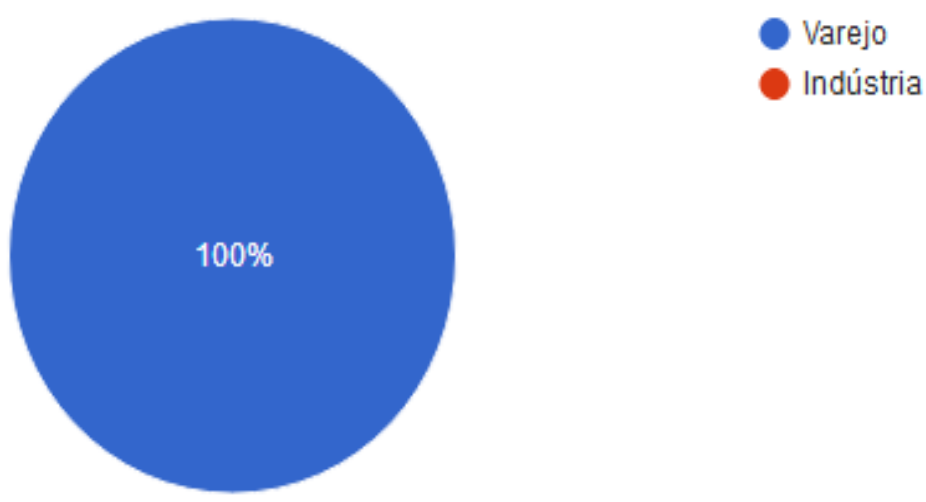

Fonte: Dados da pesquisa

$\mathrm{Na}$ figura 4, foi perguntado o segmento da empresa e $100 \%$ responderem que se enquadram no segmento do varejo, com base nas características expostas das empresas 
familiares, elas se enquadram em empreendimento de pequenos porte por não possuem um bom planejamento financeiro e estratégico no mercado.

Figura 5 - Porte da empresa

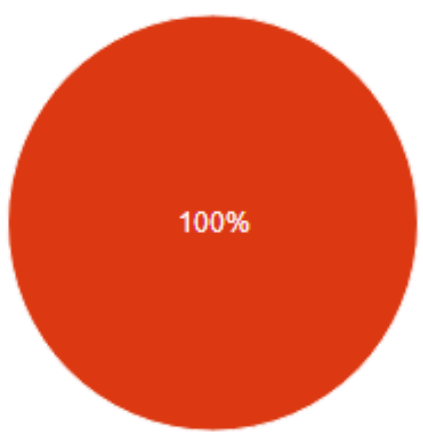

MEI- Micro Empreendedor Individual

ME- Micro Empresa

EPP-Empresa de Pequwno Porte

EIRELI-Empresa Indisvidual de

Responsabilidade Limitada

S/A-Sociedade Anonima

Fonte: Dados da pesquisa

Na figura 5, foi analisada o porte da empresa e 100\% se enquadram como ME- Microempresas, optam por essa classificação levando em consideração sua receita, pagamento de imposto e seu quadro de funcionários.

Figura 6 - Tempo de mercado

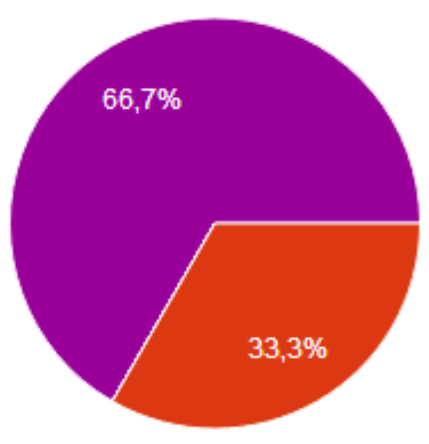

Menos de 1 ano

1 á 5 anos

6 á 10 anos

11 á 15 anos

16 ou mais

Fonte: Dados da pesquisa

A Figura 6 mostra o tempo de marcado da empresa, onde $66,7 \%$ possuem 16 anos ou mais de mercado e $33,3 \%$ possuem de 1 a 5 anos no mercado. Isso retrata novamente que os empreendimentos familiares possuem uma permanecia de mercado prolongado consequentemente resultando na viabilidade deste tipo de negócio. 
Figura 7 - Membro da familia que fazem parte da empresa

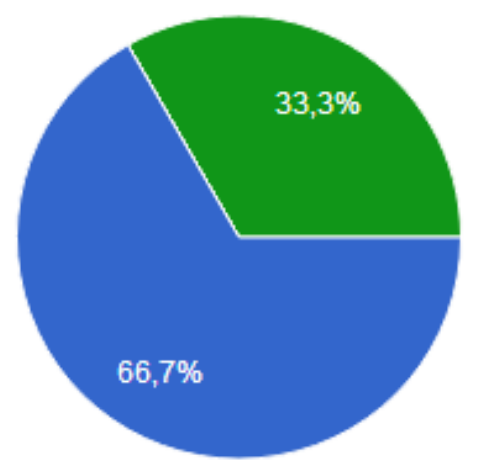

1 á 5 membros

6 á 10 mebros

11 á 15 membros

16 ou mais

Fonte: Dados da pesquisa

Na Figura 7 mostra a qualidade de membros da família que fazem parte do quadro de funcionários da empresa. 66,7\% responderam que possuem 1 a 5 membros e 33,3\% responderam que possuem 16 ou mais. Portanto todas as empresas empregam alguns de seus familiares para desempenhar determinadas tarefas de confiança na organização, no entanto algumas desvantagens são geradas acarretando problemas no desempenho da função.

Figura 8 - Fatores que influenciam diretamente na gestão

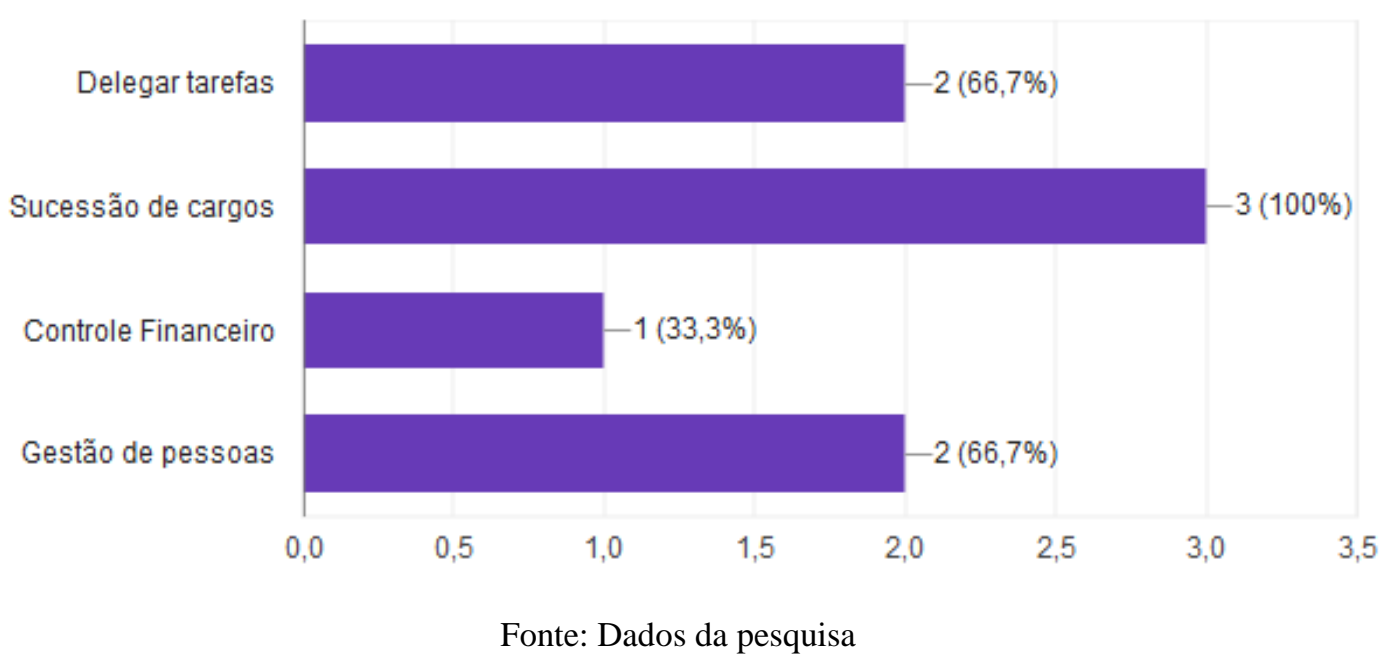

Já a Figura 8 retrata alguns dos fatores que influenciam diretamente na gestão e crescimento da organização, deste modo foram obtidos os seguintes resultados, 66,7\% alegam ter dificuldades na delegação de tarefas devido a centralização de informações, $100 \%$ afirma ter problema na sucessão de cargos, pois a terceira geração da família - netos e filhos , não têm pretensão de gerenciar o negócio, 33,3\% admitem dificuldade no controle financeiro por não 
possuírem conhecimento necessários para esse tipo de gestão e 66,7\% responderam que possuem dificuldade na gestão de pessoas, pois como seu quando de funcionários é formado, na maioria, por membros familiares a tomada de decisão e gestão das pessoas torna-se algo pessoal.

\section{Considerações Finais}

Deste modo, podemos concluir diante dos resultados obtidos na pesquisa realizada em quatro empresas da região CRAJUBAR, foi possível identificar que todas estão no segmento do varejo e possuem em evidência a gestão familiar onde as dificuldades de gerenciar o negócio estão atreladas a delegação de tarefas, centralizando informações que dificultam no melhor fluxo de trabalho, como também a sucessão de cargos, já que sua terceira geração (filhos e netos) não têm pretensão de assumir a empresa futuramente. Portanto, as empresas familiares são empreendimentos viáveis, sim. No entanto torna-se necessária uma gestão com planejamento estratégico voltado a descentralização do poder e um planejamento direcionado a sucessão da empresa no mercado.

\section{Referencias}

ADACHI, P. P. Família S.A. Gestão de empresa familiar e solução de conflitos. São Paulo: Atlas, 2006.

ANDRADE, M. M. de Introdução à metodologia do trabalho científico: elaboração de trabalhos na graduação. 6. ed. São Paulo; Atlas, 2003.

CERVO, A. L.; BERVIAM, P. A. Metodologia Cientifica. 4. Ed. São Paulo: Pearson Education do Brasil, 1996.

CHIAVENATO, Idalberto. Recursos Humanos. O capital Humano das Organizações. $8^{a}$ ed. São Paulo, Atla, 2008.

DA SILVA, Lenivaldo . Tipos de pesquisa o que é e para que serve: pesquisas são ações de buscas de conhecimentos em determinadas áreas de atuação. São expectativas e necessidades do mercado. Para obter ás pesquisas é necessário que haja a interação, contato continuo com um determinado grupo ou mercado (Fornecedores, concorrentes, consumidores, revendedores). Disponível em: $<$ http://www.administradores.com.br/producao-academica/tipos-de-pesquisas-o-que-e-e-para-queserve/5236/>. Acesso em: 16 abr. 2018. 
DONNELLEY, R. G. A empresa familiar tem suas vantagens e desvantagens, o importante é identificá-las e compreendê-las. v. 2. Boston: Biblioteca Harvard de Administração de empresas, 1976.

DRUCKER, P. (1970) "Empreendedorismo em Empresa de Negócios", Journal of Business Policy, vol $1,1970$.

GERSICK, K.; DAVIS, J.; HAMPTON, M.; LANSBERG, I. De geração para geração: ciclos de vida das empresas familiares. 4. ed. São Paulo: Negócio, 1997.

LETHBRIDGE, E. Tendências da empresa Familiar no mundo. Revista BNDES, n. 7, jun. 1997. Disponível em: http://www.bndes.gov.br/conhecimento/revista/rev707.pdF>. Acesso em: 24 abr. 2018.

Lansberg, I. De geração para geração: ciclos de vida das empresas familiares. São Paulo:

Negócio. 1997.

MARTINS, Ives Gandra; MENEZES, Paulo Lucena; BERNHOEFT, Renato. Empresas familiares brasileiras. São Paulo, Negócio, 1999.

MATTAR, F. N. Pesquisa de marketing. 3 ed. São Paulo: Atlas, 2001.

RICCA NETO, D. Da empresa familiar à empresa profssional. São Paulo: CL-A Cultural, 1998.

SCHUMPETER, A. Joseph. Capitalismo, socialismo e democracia. Trad. Sergio Góesde Paula. Rio de Janeiro: Zahar Editores, 1984.

SEBRAE. As características de negócios familiares: Empresas familiares têm estrutura enxuta. Conheça os pontos fracos e fortes desse tipo de negócio. Disponível em: <http://www.sebrae.com.br/sites/PortalSebrae/artigos/as-caracteristica, $\quad$ 48e89e665b182410 VgnVCM100000b272010aRCRD>. Acesso em: 16 abr. 2018.

OLIVEIRA, L. S. Tratado de metodologia científica: projetos de pesquisas, TGI, TCC, monografias, dissertações e teses. 2. ed. São Paulo: Pioneira, 1999.

OLIVEIRA, D. de P. R. de. Empresa familiar: como fortalecer o empreendimento e otimizar o processo sucessório. São Paulo: Atlas, 1999.

SEBRAE. Iniciando um pequeno grande negócio. Brasília: SEBRAE, 2001.

SILVA, A. C. R. Metodologia da Pesquisa aplicada à Contabilidade. São Paulo: Atlas, 2003.

VANZOLINI, Fundação. 95\% das empresas familiares são extintas no processo de sucessão à segunda ou terceira geração. Disponível em: <https://vanzolini.org.br/noticia/95-das-empresasfamiliares-sao-extintas-no-processo-de-sucessao-segunda-ou-terceira-geracao/>. Acesso em: 18 abr. 2018.

\section{Como citar este artigo (Formato ABNT):}

CAMPOS, Suzana Siebra Alves; SARAIVA, Piedley Macedo. Empreendedorismo Familiar: Como esse Modelo de Gestão pode Afetar a Empresa. Id on Line Rev.Mult. Psic., 2019, vol.13, n.44, p. 525538. ISSN: 1981-1179.

Recebido: $12 / 02 / 2019$

Aceito 13/02/2019 